\title{
Pandemics and the development of scientific methods in the history of epidemiology
}

\section{Pandemias y el desarrollo de métodos científicos en la historia de la epidemiología}

\author{
Alfredo Morabia \\ editorajph@qc.cuny.edu \\ Editor in chief American Journal of Public Health. New York University, New York, EEUU
}

The Covid-19 pandemic has made me see the history of epidemiology differently ${ }^{1}$. Pandemics are such impressive events that they can exert urgent pressure to identify new modes of research and new methodologies to replace methods that have failed in the past. Some examples seem to corroborate this idea.

\section{Citation: Morabia A. Pandemics and the development of scientific methods in the history of epidemiology. Colomb Med (Cali). 2020; 51(3):e104564. \\ http://doi.org/10.25100/ cm.v51i3.4564}

Copyright: @ 2020. Universidad del Valle.

(c) $(1)$

Conflicts of interest:

None

Acknowledgments:

I thank Catarina Cordeiro for comments and suggestions on an earlier version of this article.

Corresponding author: Alfredo Morabia, MD, PhD, Barry Commoner Center, Queens College, City University of New York, Remsen Hall, Room 311, 65-30, Kissena Blvd., Flushing, NY 11365. e-mail: editorajph@qc.cuny.edu

\section{Supplementary material:}

https://www.youtube.com/ watch?v=G Z9w1u5yIU

\section{The plague}

There is no doubt that one of the most important events in the history of science occurred in the 17th century when population thinking was discovered. All human and social sciences such as sociology, demography, Darwinian biology, political economy, statistics and epidemiology, have their origin in the discovery that dictates that events in populations can be predictable and have a probability of occurrence. Then the occurrence of events in populations can be quantified, can be compared between populations and can be the source of scientific knowledge. This true revolution in scientific thought is a consequence of changes in society that occurred due to plague pandemics.

Since the great pandemic of the 14th century, outbreaks of plague in Europe caused great confusion in cities and increasingly threatened existing powers. It was the case of the monarchical society of England. In the event of an outbreak of plague in London, the nobles, the wealthy, and the army left the city, where only the poor remained. The situation became chaotic in London. It was quickly clear that there was a certain chronological regularity in the outbreaks. They started with a small but growing number of deaths in some parishes before spreading throughout the city. In the 16th century the city of London began to collect data on the number and location of pest deaths ${ }^{2}$. The system was improved in the 17th century and extended to all cau- ses of death, making it possible -by the end of the century- to organize orderly outings from London in the event of an outbreak of plague, preventing chaos. These data were printed and placed on the walls of the city. They were called the "Bills of mortality", death posters. In this process, a temporal series of mortality data was established in London over decades.

Back then only large merchants knew how to analyse quantitative data. One of them, John Graunt, analyzed the death charts of a 50-year period. He observed what was known about the plague: deaths fluctuated cyclically even if they did so irregularly. But he also discovered something that no one had ever seen or suspected before: deaths from some diseases, such as what we now call tuberculosis, occurred with great regularity. Every year there were more or less 2,000 deaths from tuberculosis. The number of deaths from that disease was predictable from year to year ${ }^{3}$. It is not a simple phenomenon to explain. On the individual level, death 
Pandemics and the development of scientific methods in the history of epidemiology

is a random, unpredictable event, and individual observations were all that doctors had had until then. They could not suspect that populations had different characteristics from the individuals that made them up.

Then, the surveillance system for outbreaks of plague allowed the constitution of a temporal series of quantitative data for the first time in the history of humanity. And these data were the essential condition for the discovery of populational thinking, which is constitutive of all human and social sciences.

\section{Cholera}

Cholera became an endemic disease in certain parts of Asia, but in the 19th century the means of transportation allowed sick people to travel from, for example, Bombay, India, to Marseille, France, or from Rotterdam, Holland, to New York or Cartagena, Colombia. Then, the cholera pandemics began. The third pandemic (1841-1859) reached Europe and from there it went to Central and South America. Cholera was terrifying because it killed 50\% of cases in a few hours, due to diarrhoea and vomiting. In emerging public health, people thought that a form of foul-smelling air pollution, made up of miasmas, caused this disease. Those who were susceptible died, the others did not, but no one could predict who was susceptible.

Cholera was of such priority to 19th century scientists that they all came together in a society to study and combat it and called it the London Epidemiological Society. One of its members, John Snow, had become convinced that cholera was caused by some tiny living organisms that were transmitted by water, food, or dirty sheets. Snow performed a now-famous study -but different study from the cholera outbreak investigation around the Broad Street water pump: Snow compared the cholera mortality of residents of the same London parishes but who bought their water from different companies, one that pumped dirty water from the Thames in central London, and other that pumped clean water from the Thames as well, but outside London. This was the first population-based comparative study of this dimension, there was an enormous methodological impact in the history of epidemiology, and it was a consequence of cholera pandemics.

\section{The Spanish Flu of 1918}

Until 1918, public health professionals were state employees or health officials, who, in the United States, belonged to the Navy. In April 1918, Wade Hampton Frost was an officer of the US Public Health Service when surgeon general Rupert Blue charged him with responsibility for the Influenza Pandemic Task Force. Frost conducted a massive house-to-house survey of 18 locations in the US and established the prevalence of infection in the population in the fall of 1918. At one time, the Johns Hopkins University School of Hygiene and Public Health admitted its first students on October $1^{\text {st }}, 1918$. William Henry Welch, the founder of the School, hired Frost as director of the first department of epidemiology in history in September 1919. Frost once again became the first "professor of epidemiology" in the United States. I know of no evidence of the connection between the flu pandemic and the academicization of epidemiology, and more generally, of public health. Furthermore, Frost is remembered today first and foremost for his work on tuberculosis and not for his studies of the flu pandemic. But both Welch and Frost had been very active in the federal response to the flu pandemic, and by the years 1919-1920 all of Frost's publications were about the flu. In retrospect, then, we can consider that the frightful pandemic of 1918 stimulated the emergence of an academic and parallel extension to the public service dedicated to public health and epidemiology. Almost all subsequent methodological developments in epidemiology were made in public health schools and in academic epidemiology ${ }^{4}$. 


\section{Discussion}

The examples of the plague, cholera, and influenza of 1918 seem to indicate that these pandemics stimulated the development of new methods in epidemiology. Tuberculosis and HIV / AIDS cases indicate the same phenomenon ${ }^{5}$. Despite the above, it can be argued that pandemics and methodological developments actually have different histories that perhaps only seem to be associated in time.

For example, the memory of methodological developments makes us associate them retrospectively with contemporary pandemics. In favour of the causal connection between pandemics and methodological developments is the absence of counterexamples of minor epidemics that would have stimulated larger methodological developments of equal magnitude to those I described for pandemics. It is conceivable that the critical conditions of a pandemic stimulate a new look at the old methods that failed to prevent disaster. Above all, a common feature of pandemics is the immediate, extraordinary, surrounding and inevitable presence of the death of family members, neighbours and friends. This situation did not occur in epidemics such as smallpox in the 18th century, or in infectious diseases of the 19th century such as diphtheria or measles ${ }^{6}$, or with cancer and cardiovascular diseases of the 20th century. They were true epidemics that caused many deaths and suffering, but they did not stop the movement of society and did not make people urgently reflect on the limits and dead ends of existing methods.

My thesis has yet to be validated by the Covid-19 pandemic. Perhaps we are witnessing a change. Never in the past have we collectively considered what an epidemic curve is, what group immunity is, and how we can act together to modify the progression of infection. But all of us also realized that modest workers became heroes who faced higher mortal risks so that others continued eating and were treated in the health services. Perhaps we emerged from this crisis with greater awareness of the fact that health inequalities are population-based and not individual phenomena. If population thinking became common, it would have enormous consequences for the society that we will build when this painful experience is over.

\section{References}

1. Morabia A. Enigmas of health and disease: how epidemiology helps unravel scientific mysteries. New York, NY: Columbia University Press; 2014.

2. Heitman K. Authority, autonomy and the first London bills of Mortality. Centaurus. 2020; 62(2): 275-284. doi: 10.1111/1600-0498.12305

3. Graunt J. Natural and political observations made upon the bills of mortality. Johns Hopkins University Press; 1662.

4. Morabia A. Has epidemiology become infatuated with methods? a historical perspective on the place of methods during the classical (1945-1965) phase of epidemiology. Annu Rev Public Health. 2015; 36:69-88. doi: 10.1146/annurev-publhealth-031914-122403.

5. Morabia A. Pandemics and methodological developments in epidemiology history. J Clin Epidemiol. 2020; 125: 164-169. doi: 10.1016/j.jclinepi.2020.06.008

6. Hardy A. The epidemic streets. Infectious disease and the rise of preventive medicine. 1856-1900. Oxford, UK: Clarendon Press; 1993. 